The Geneva Papers on Risk and Insurance, 17 (No. 64, July 1992), 299-313

\title{
Rethinking Risk Management ${ }^{*}$
}

\author{
by $\mathrm{H}$. Felix Kloman**
}

\section{George Smiley \& Franklin D. Roosevelt}

What do George Smiley and Franklin D. Roosevelt have to do with risk management? A great deal, as it turns out.

George Smiley, as spy mystery readers know, is the leading character in many of John LeCarre's books. In his latest, The Secret Pilgrim, George Smiley posed “... the question I had been asking of myself for most of my working life, but had never managed to express, such as, did it do any good? And what did it do to me? And what will become of us now?" I have been asking myself these same questions in connection with my own 35 year pilgrimage toward that elusive Grail, risk management. George Smiley's questions are important because all of us need to step back occasionally from our labors and find some acceptable answers. These questions, therefore, are most appropriate for a review of the discipline of risk management as it has developed over the past and as it is likely to develop in the future.

Franklin Roosevelt's connection comes from two recent ideas. The first was a suggestion by Barry Katz that "the ultimate objective of the study of medicine is not medical knowledge, but health, and the purpose of political science is justice". Katz's comment suggests there may be a corollary for risk management, one that may have eluded us thus far. Is it enough to say that our objective is simply to "reduce costs", the traditional goal? Is there something broader, along the lines of Katz's thinking? My own personal answer was found in the 1990 Annual Report of USAA, a highly successful personal lines insurance company in the United States. That Report commemorated the 50th anniversary of the "four freedoms" of Franklin Delano Roosevelt: freedom of speech, freedom of worship, freedom from want; and, freedom from fear. When these were first enunciated at the outset of the second world war, the U.S. Government commissioned Norman Rockwell to illustrate each of them. These illustrations were reproduced in the USAA Annual Report. According to the illustrator, the last - freedom from fear - was apparently the most difficult to paint. His final effort showed a mother and father tucking children into bed in a scene of security and tranquillity, even as the father is holding a newspaper with headlines of the bombing of London.

* This paper has been drawn from comments presented to the World Insurance Congress, London, July, 1991.

** Tillinghast, Stamford, Connecticut, USA. 
It occurred to me then that perhaps the real objective of risk management is to reduce fear of the unknown and the unexpected, and to create confidence in the future. It is certainly not simply the technical understanding of risk nor making financial provisions for alleviating the pain of loss.

To carry this theme further, could it have been some inchoate fear of the future that spawned the incredible materialism and greed that have been the symbols of the past decade? Are we so afraid of the future that, in compensation, we devour the present, and, perhaps ironically, make a secure future even less possible?

If so, asking of ourselves the questions of George Smiley and considering the broad goal of "freedom from fear" enunciated by Franklin Roosevelt, we can conclude that there may well be a more significant role for risk management - to restore our faith in ourselves and our futures, and to reestablish our confidence in our abilities to survive and prosper.

This is why rethinking risk management is so important today, in a period in which we are beset by uncertainties. If risk management can contribute to the larger goal of creating new confidence - reducing fear - it will be important to all of us both individually and in the organizations and political structures in which we participate.

\section{Past as prologue}

\subsection{The fifties through the eighties:}

In May of 1991, R. S. G. Strutt completed a paper entitled "A Definitive Technique for Risk Assessment?" It was a contribution to the first annual conference of the Institute of Risk Management in London. This paper included a detailed review and analysis of risk management literature and thinking over the past 30 years and concluded with the provocative idea that, in some respects, the risk management discipline has become stalled on its road to further progress. This led me to conduct my own walk through the early history of risk management to see whether or not he was correct.

My first introduction to the term "risk management" came in 1958, after joining an insurance brokerage firm in Philadelphia. As part of my training, I was given a folder of news articles, including one from The National Underwriter reporting on the comments of an insurance professor, Dr. Wayne Snider. In a speech on November 24, 1955, he suggested that "the professional insurance manager should be a risk manager", reporting to the treasurer of an organization, with four expanded functions: administrative, engineering, actuarial science and insurance. Another article in the folder came from the Harvard Business Review in 1956. Entitled "Risk Management: New Phase of Cost Control", it was written by Russell Gallagher, then insurance manager for Philco Corporation. In this article, Mr. Gallagher outlined the "Principles for a Workable Program of Risk Management". Even today, I am struck by the continued pertinence and applicability of his comments of more than 30 years ago. Philadelphia continued to be the focal point of the early development of risk management as it relates to insurance, at both the University of Pennsylvania and Temple University. Professors at both institutions pushed the context of risk management in the late 1950s and early 1960s, especially with graduate seminars. Academics at Penn first identified Henri Fayol, a Frenchman who wrote in 1916, as one of the early thought leaders of what has become risk management.

The next significant development in risk management came not in the United States but in Canada, where Douglas Barlow, then risk manager at Massey-Ferguson, introduced 
in 1966 in the idea of "cost of risk" as a new performance measurement tool. He defined "cost of risk" as the sum of insurance premiums, self-insurance costs, risk control expenditures and administrative costs, and compared this "cost of risk" to both assets and revenues. This idea has slowly developed to the point at which an annual cost of risk survey is undertaken in North America. Today, in many organizations, "cost of risk" is used as both an internal and external benchmark for performance measurement.

In 1971, shortly after embarking on a new career as a risk management consultant, I wrote the following in "The Revolt of the Risk Manager":

Until the risk manager can be completely free of his real and psychological ties to insurance and the insurance industry, he will not be able to perform the risk management function...

In this article I suggested 10 concrete steps for change, two of which were to break the umbilical cord to insurance and to redefine the scope of risk management. These same ideas were carried forward in another article that I authored entitled "The Risk Management Revolution" which appeared in Fortune magazine under the sponsorship of the Risk \& Insurance Management Society in July, 1976.

The mid-70s and the early 1980s also saw a blossoming of risk management in Europe. Gustav Hamilton, then the risk manager of Sweden's Statsforetag, developed a "risk management circle" in 1974, an early attempt to break the boundaries of confined insurance thinking. Arguing for a "new and collective view of risks and damage", Hamilton combined safety and insurance viewpoints. In Switzerland, Orio Giarini, then at the University of Geneva, presented a paper with a macro-economic view of risk management at a London conference in 1976. He suggested that risk management in the post-industrial society will address the increasing vulnerability of economic systems and the problems arising out of the excessive specialization of function. To Giarini, risk management involved "reconstructing a puzzle" and "reinforcing the strategic capability of a form". $\mathrm{He}$ concluded that "some type of societal risk management has to come to the rescue of economic... in order to restore better navigation in the troubled sea of the world economy".

Also in Switzerland, Matthias Haller, at the Graduate School of St. Gall, was defining risk as "the possibility that the positive expectations of a goal-oriented system will not be fulfilled" and that risk management is a discipline that will assure to any organization that it can provide internal security, external security and security to others.

And in England in 1980, Neil Crockford wrote "An Introduction to Risk Management", one of the best texts to date. He too suggested that risk management is multidisciplinary, that risk must be managed "in all its aspects", and that "each specialist sees risk management in terms of his own special interest, with the result that the message is fragmented among a number of 'sects', each claiming to preach it all". Risk management then becomes a linking function, coordinating diverse disciplines and skills to address both constant and variable risks. This book was followed by Paul Bawcutt and Jim Bannister's "Practical Risk Management" (1981), a continuation of the overall approach espoused by Crockford. They argued that the management of "future uncertainty" is everyone's responsibility and that the constituent disciplines of risk management include probability theory, economics, operations research, systems theory, decision theory, psychology and behavioral science. 
In the 1980s risk management expanded rapidly on a global basis and well beyond its traditional insurance boundaries. Risk analysis and risk assessment have become far more sophisticated, using new tools of decision theory. System safety and pressures on health care institutions have created new approaches to risk and quality control, for both services and products. The growing complexity of financial arrangements has led to new techniques for financing risk ranging from swaps, hedges and collars to financial reinsurance.

\subsection{Organizations in Risk Management:}

Organizations representing the various practitioners of these new modes of risk management have also grown strong. What was initially the National Association of Insurance Buyers became the American Society of Insurance Management and then the Risk \& Insurance Management Society (RIMS), as it is known today, a group of over 3,500 risk and insurance managers in North America. PRIMA, the Public Risk Management Association, represents practitioners from public entities in North America.

In Europe, organizations of risk managers such as the Association of Insurance and Risk Managers in Industry and Commerce (AIRMIC) and AEAI have led the development of the discipline. The Geneva Association and the Institute of Insurance Economics, both in Switzerland, have created new economic perspectives and, finally, the recent establishment of the Institute of Risk Management in London provides a global professional forum for all individuals interested in the discipline.

Perhaps even more important than these organizations has been the creation and growth of other groups not specifically connected with the insurance side of risk management. The Society for Risk Analysis, headquartered in McLean, Virginia, is a global organization of individuals interested in risk assessment. The Institute for Corporate Risk Management in Chicago focuses on the management of interest rate, credit and currency risks and the Center for Risk Management, in Washington D.C., is a public policy think tank on environmental risk. There are university risk management centers at Virginia, Harvard, Georgia State, and Southampton (UK), among others.

There is no doubt, then, that the discipline has evolved significantly since the early 1950s. It has been defined and redefined, and, at every step, it is becoming broader in scope.

\subsection{Definitions and Current Comments:}

In 1974, I suggested that risk management was "the art of making alternative choices, an art that properly should be concerned with anticipation of future events rather than reaction to past events". Most of the other definitions in use have had a clear insurance focus, since so many of the early proponants actually came out of the insurance industry, but the definitions have become slowly broader and more inclusive of late.

Another theme in many of these definitions was that of "common sense".

- George Head, writing in 1980, suggested that "risk management is simply good common sense in coping with the possible and actual daily mishaps, and occasional major disasters, that lead to financial losses and unfulfilled plans for individuals and organizations - indeed for our society as a whole".

- Ted Siver, writing in 1991 suggests that "basic risk management in mostly common sense". 
- Neil Crockford, "There is nothing very complicated about risk management" (1980).

The recent developments in the past three years provide a most dramatic indication of the blossoming of risk management as a discipline. Five writers have recently addressed some of the issues affecting the future development of the discipline.

The first is Rod Strutt in the paper referred to earlier. After re-reading the Russell Gallagher article of 1956, he reached the reluctant conclusion that, "35 years on, it is readily apparent that nothing fundamental has changed". He went on to say that:

If the risk management profession is to be relevant to the needs of organizations and society in the 1990s, it is imperative that the umbilical cord (to insurance) is broken. Our inability to achieve this is primarily due to the lack of a theoretical basis for risk management. This remains the overriding priority.

In 1990, Tony Burlando, the Risk Manager of the Hillman Company in Pittsburgh, chaired a RIMS Task Force addressing the need for a theoretical basis for the discipline and developed a number of conclusions in an article in Risk Management magazine in April 1990. The task force concluded that:

- "Risk Managers are in the business of managing the future",

- There should be efforts undertaken to correct the "mismatch" between risk management definitions and actual practice,

- A new mission of risk management should be to "address harmful uncertainties", deliberately omitting the word "manage" in the mission statement.

Another contribution has come from Professor Yacov Haimes, Director of the Center for Risk Management of Engineering Systems at the University of Virginia. In a paper on "Toward a Holistic Approach to Risk Management" in 1989 he emphasized the requirement for "cross-disciplinary" contributions to risk management and, in a follow-up article entitled "Total Risk Management" in Risk Analysis in June 1991, he defined risk management as :

"A systemic, statistically based, and holistic process that builds on a formal risk assessment and management and addresses the set of four sources of failures within a hierarchical multi-objective framework:

(1) hardware failure

(2) software failure

(3) organizational failure

(4) human failure".

The Haimes conclusions were that the field of risk analysis will lose some of its current mystique, that participating disciplines will find more common ground, and that the public will have a greater appreciation and understanding of the process of risk assessment and risk management.

Paul Portney, the acting director of the Center for Risk Management, in Washington, D.C., in operation for now for five years, has focused the Center's efforts on answering two of the "most fundamental questions facing society":

- What should society be trying to accomplish with the billions of dollars it spends on risk reduction each year?

- How can the nation better achieve the objectives it most values? 
Through research in technological disasters, environmental risk, nuclear risk and other macro risk problems, the Center has brought a high level of visibility to risk management in Washington. It has an Advisory Council that includes Senator Bill Bradley of New Jersey, former Governor (of Colorado) Richard Lamm and William Ruckelshaus, former head of the Environmental Protection Agency. The five major issues that the Center is addressing include:

(1) What social goals are being furthered through environmental health and safety programs?

(2) How can the net benefits of progress toward particular social goals be gauged?

(3) How do different goals constrain or impede one another, and how can policies yielding different sets of benefits be balanced?

(4) How can the tradeoffs among different risk reduction programs be made more apparent and conflicts among them resolved in a more palatable manner?

(5) Which emerging strategies and technologies might be most effective for improving the efficiency and fairness of risk reduction measures - that is, making tradeoffs less onerous?

The last of the more recent writers on risk management is Vernon Grose, whose 1989 book "Managing Risk: Systematic Loss Prevention for Executives" brings a system safety and qualitative approach to risk assessment of all risks. Using scenario analyses developed by operating managers, his SMART system significantly broadens the scope of risks to be considered. His book also cautions against the overuse of numerical probabilities in risk assessment, arguing that:

(1) Complexity in human behavior cannot be reduced to numbers

(2) Numbers for the intricacy of real life will always oversimplify

(3) Lack of applicable data will often force dishonest guessing

(4) Decision makers may inadvertently substitute numbers for reasoned judgment

(5) Risk can be too simplified and unrealistically traded off against benefit by relying on numbers.

The intensity and quality of the commentary on risk management over the past three years, as evidenced by these five writers, indicates that a rethinking of risk management is taking place right now.

\section{A new framework for risk management}

Roy Amara and Andrew Lipinski, writing in 1983, illustrated why risk management is becoming an essential discipline in an uncertain society:

The environment the corporation faces today - and will face increasingly in the future - is markedly different from the past. The most important difference is the much higher levels of uncertainty at which they operate. Corporate managers are now confronted with a much wider variety of economic, social, regulatory and competitive factors influencing performance. At the same time, the level of understanding of how these factors, singly and jointly, influence achievement of corporate objectives is not keeping pace with management needs. 
Based on his reading of the literature, Rod Strutt reached very much the same conclusion:

- There is already a strong theoretical base for risk management.

- Risk management is becoming more holistic, proactive, systemic - a focal point for an organization's ability to adapt to change.

- The broad and narrow views of risk management are being reconciled by making the organization and its inter-relationship with the environment the focal point.

- Risk management is becoming identified with general management.

- Risk management is becoming more strategic, part of the planning process.

Risk management will therefore probably be a synthesis of already developed or developing skills and specialties:

- General management theory

- Insurance management, actuarial and risk funding theory and practice

- Macro risk assessment and decision risk theory

- Quality assurance methodology, for products and services

- Loss prevention, system safety, and security engineering

- Crisis or contingency planning

- Financial risk maneuvers, including hedging and swaps.

For public acceptance and understanding, we need brief, clear and concise definitions of both "risk" and "risk management". In the past these have been either too long or too connected to the speciality of the definer. I suggest the following for "risk":

Risk is the compound estimate of the probable frequency, severity, and public perception of harm.

This is a paraphrase from a paper of William Lowrance in 1989 and includes "public perception" in the equation. While this adds an inherently non-quantifiable element, it is clearly evident today that the public understanding of and response to risk, whether rational or irrational, may be more important to any eventual action that we take than the mechanical estimates of experts on probable frequency and severity. Others agree: "The full dimension of risk cannot be captured by the probability of adverse consequence, because that misses the human element" (Covello, Menkes and Nehnevajse).

The second definition is:

Risk management is a discipline for living with the possibility that future events may cause harm.

This is a paraphrase of a definition from a 1977 book by William Rowe. The important words in this definition are "living with". We must realize that risks are a continuous and ever present element of life. We must learn how to live with them rather than presuming that they can all be avoided.

Both definitions are deliberately brief and simple. The more complex a definition, the more difficult it will be for laymen to understand.

The key elements, then, of risk management come from the traditional definitions: risk assessment, risk control and risk financing. In risk assessment, we answer the 
question: What can go wrong? In risk control we answer the question: What can we do about it? And in risk financing we answer the question: How do we pay for it? As Aaron Wildavsky has said, "The trick is to discover not how to avoid risk, for this is impossible, but how to use risk to get more of the good and less of the bad. The search for safety is a balancing act".

Defining the different types of "future events" that may cause harm requires that we detail what we mean by risk management. It should be a holistic endeavor, one that looks at all risks and their inter-relationships including primary, secondary and tertiary effects. Exhibit 1 is one way of looking at holistic risk management. It shows the broad range of different types of risks that must be addressed by a risk management function including operational, legal, political and financial/market risks.

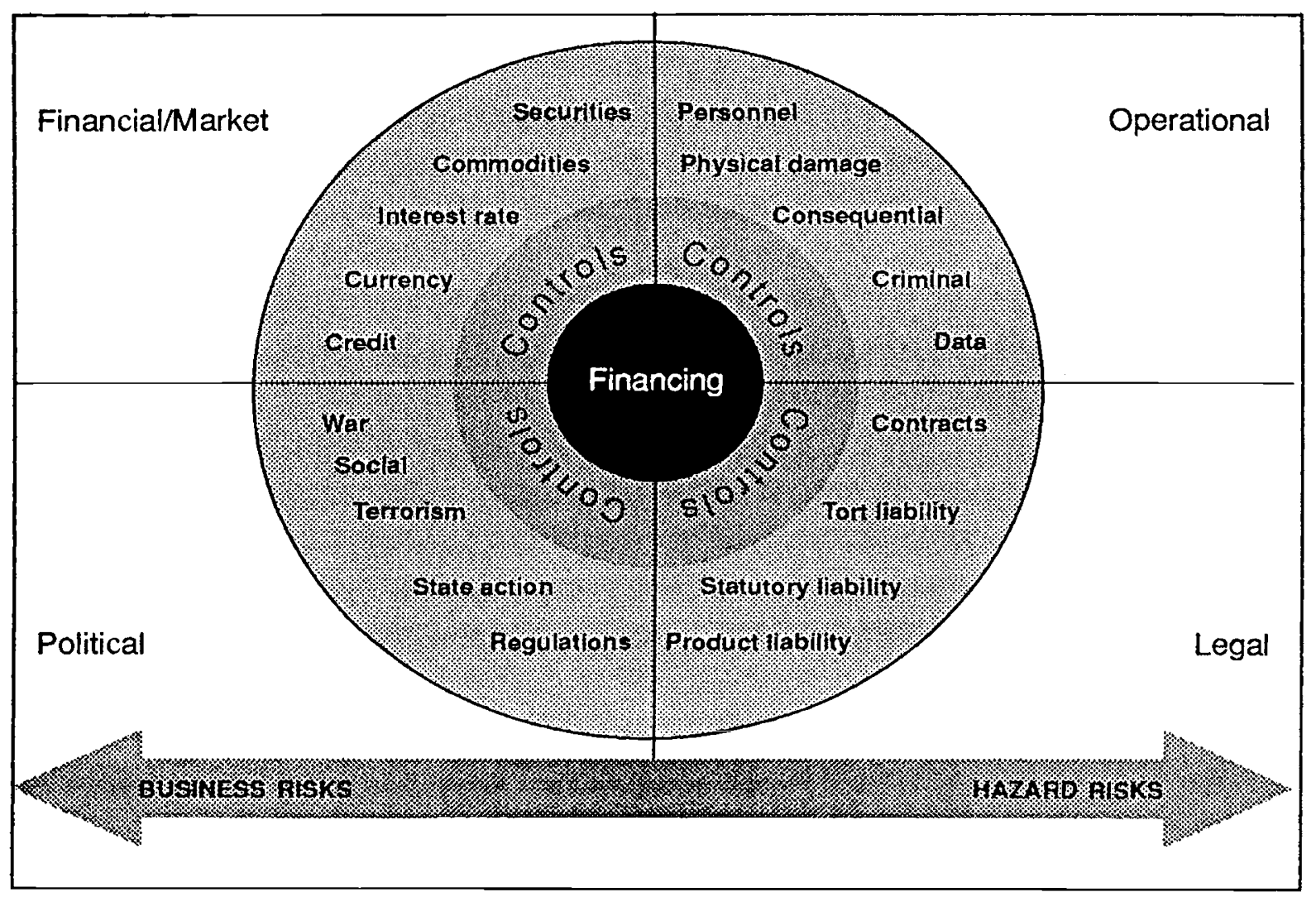

While there may be numerous other ways of looking at these areas of risk, there is no question but that risk management can no longer be defined as focusing on but one or two of these areas.

\section{Rethinking the future of risk management}

As I see it, there are five factors that could have a significant effect on the continued development of risk management as an important organizational discipline. They are risk communication, the problem of balkanization of risk management practice, short-term versus long-term thinking, the effect and threat of catastrophes, and the role of the insurance industry. 
First, coherent risk communication is of growing importance. We live in a society in which the problem of public misperception of risk can lead to disastrous consequences. According to Harvey Zapolski:

Our political system may be hazardous to our health. It hunts small risks ruthlessly while permitting much bigger ones to exist relatively unmolested. It invests billions, seeking unattainable safety, while failing to provide the resources necessary to protect our future. Hardly anyone is served by the collective mania with risk. Many may be harmed by what goes undone.

Our media is crowded with the conflicting estimates of experts. Some warn us, almost like religious fanatics, that "the end is near". Others argue that the future could not be rosier. Are we becoming a "risk-befuddled society", as suggested by Dana Murphy? As a result, are we becoming inherently more risk averse and less rational about our responses? We have already recognized there is a tendency to over-emphasize risks with low probabilities and under-estimate those with high. How else can we justify the some 50,000 deaths a year in North America from auto accidents and the estimated 500,000 deaths attributable to the tobacco habit?

What all of us will have to understand is that there may be, in effect, a law of conservation of risk at work. If, for example, we wish to continue the benefits of relatively inexpensive electric power, we must accept either the risks inherent with nuclear facilities or those inherent in fossil fuel-fired facilities, at least until and unless fusion, solar power or other alternatives are economically feasible. Even then, I suspect that we will still find risk tradeoffs. As William Lowrance has argued, risks are interrelated. They must be compared, using his three rules of risk assessment:

- Construe risks broadly

- Don't merely displace risks (substituting one for another)

- Overall: Confront and compare risks.

A risk-cost-benefit equation must be developed within the understanding of overall accountability. We are all responsible, as so aptly stated by Walt Kelly's Pogo: "We have met the enemy, and he is us".

Improved risk communication will be an over-riding objective of the 1990s. Within individual organizations, risk managers should strive to communicate risks intelligently to senior management, operating management, employees, the communities in which they operate and to customers and suppliers.

Second, risk management may become more balkanized, or fragmented, rather than consolidated. Lack of communication and misunderstanding - even conflict - among key practitioners must be overcome if we are to reach our joint goals.

The form of risk management that has come out of insurance is altogether too focused on insurance and financing. As Ted Siver has pointed out, "risk finance can throw money at the problem. It can't replace limbs or lives, or erase the trauma or the immeasurable inconvenience and hidden costs that accompany any major loss".

Public policy risk management often loses its listeners in arcane and complicated risk assessments that are difficult for the general public to fathom. Also, the public policy types often lack a realistic view of pragmatic financing solutions. 
Those involved in financial risk management have shown an over-concern with the complex tools to spread or hedge interest rate, credit or currency risks. They too need to listen to others.

Finally, those from the safety and security side are often too moralistic about their objectives, without showing a reasonable regard for economic limitations.

Each of these brands of risk management believe themselves to be the most important, yet it is through cross-fertilization that each will be able to grow. The risk is that over-specialization may reduce, rather than enhance, communication.

The fragmentation of the discipline continues to be a threat, at a time when consolidation is essential.

Third, risk management inherently involves long-term, not short-term thinking. And yet is appears that short-term thinking still dominates economic and political decisionmaking today.

Last year, Christ Best, the editor of Foresight, wrote:

Why should a business which plans its activities no more than five years ahead, at the most, be concerned about the latent disease responsibilities which it might be incurring but which are unlikely to manifest themselves for ten, twenty or more years? Or about the accidents which have a 1 in 150 years probability? This is the essence of the risk management problem...

Thus, as a result, too many risk managers play the short-term game today. We must begin to assess the long-term costs of today's actions. For example, we want many of the benefits connected with the wide variety of chemicals that have been developed over the past 40 years, but are we willing to accept some of the latency problems that are the inherent costs of these benefits? How are these costs most fairly borne? If we acknowledge the benefits of inexpensive electricity, as mentioned above, are we willing to tolerate the risks inherent in the unsolved problems of nuclear waste disposal and the contribution of fossil fuel plants to the alleged global warming?

The problem, as Best so aptly puts it, is difficult. In a market economy we ask our entrepreneurial organizations to create new products and services, in the search for a better life. But can "the market", with its avowedly short-term rewards, serve as a mechanism for asking these same organizations to measure - and price - the possible negative effects that may occur some 20 to 50 years out? Given our system, managers are simply not interested in potential negative effects that far in the future. This inevitably leaves it to "society" to take responsible steps, but in a global economy there is no single expression of society's wishes, and no mechanism for effective enforcement! In addition, there are economists who argue that the current benefits produced by industry will far outweigh any long-term negative results. Who is to judge?

This brings up some challenging questions:

- How can we require more responsible long-term estimates of risk without shackling creativity and entrepreneurial drive?

- Who within an organization is willing to become the long-term risk "wet blanket", when all current constraints are short-term and when our long-term prognostications are weak, at best? 
- Can or should national governments serve in a regulatory capacity, given their propensities for bureaucracy and the stifling of initiative? Will their regulations be fair in view of the growing inter-connections of a global economy? The multi-national decision to phase out the use of the chlorofluorocarbons that allegedly affect our ozone layer may be one example of a successful global response, but there are too few of these. All too often, national regulation simply appears to restrict the companies in a single jurisdiction, to the benefit of competitors in other jurisdictions.

- Can we assume that unfettered competition will create, in time, its own solutions for the inevitable long-term risks, or does the current pre-eminence of the capitalistic system pose even more significant problems for this earth?

- Should we attach a modest "tax" to each product or service to support a common research effort on risks and their possible controls? Could this become a future form of global "insurance", since it could involve some form of financing to alleviate the suffering/losses of those affected, should risk become loss? Could such a mechanism be created through conventional market forces?

These questions, quite obviously, have no immediate answers. As they are developed they will certainly affect the risk management discipline.

Fourth, the effect of catastrophes on risk management will be significant. Our belief in progress and the skill of technology to improve life is becoming more overshadowed by our inability to prevent catastrophes. The risk of technological catastrophe appears to be increasing, witness Bhopal, Seveso and Chernobyl. At the same time there are arguments that seismic risk is increasing as well, witness the recent eruption of Mt. Pinatubo and the loss of Clark Air Force Base in the Philippines. Herbert Tiedemann, commenting at the World Insurance Congress in London in July 1991, suggested that "earthquake activity is likely to increase by a factor of 6 to 10". Finally, climatological losses, including floods and windstorms, have been much more apparent of late in North America, Europe and Asia.

It is important to remember that catastrophes are not only possible, they are probable. William McNeill, writing in Daedalus, has suggested that catastrophe is a continuing element in an uncertain life.

"Famine, epidemic and/or war have affected nearly every participant in civilized society at some time. Despite all the skills we now command, life immune from exposure to one or more of these catastrophes remains unusual. Perhaps we should recognize that risk of catastrophe is the underside of the human condition - the price we pay for being able to alter natural balances and to transform the face of the earth through collective effort and the use of tools. It certainly seems as though every gain in precision in the coordination of human activity and every heightening of efficiency in production were matched by a new vulnerability to breakdown. If this is really the case, then the conservation of catastrophe may indeed be a law of nature like the conservation of energy."

How can we "predict" what may be almost unpredictable? William McGannon, the risk manager of NOVA Corporation of Alberta, in Canada, has an interesting set of suggestions for predicting catastrophes. He offers that "any corporation worth its annual profit" will have: 
- Three near misses per $\$ 1$ million of revenue.

- Two incidents per $\$ 100$ million of aggregated revenue. An incident is an event that calls on the emergency response plan in some form.

- One major loss per $\$ 8$ billion of aggregated revenue. A major loss is defined as representing one percent of annual sales revenues or one percent of retained earnings, whichever is larger.

- One catastrophe loss every ten years. A catastrophe is defined as one that is equal to 1.5 times annual profit and/or includes one or more serious injuries or deaths to employees.

How should the risk manager and the risk management function treat the risk of catastrophe? Is it worth the effort to predict and prepare? If Bill McGannon's figures are even close to correct, the answer is certainly "yes".

Thomas Gilovich comments: "We are battling against the tendency of the human brain to impute structure and coherence to random patterns, to be more impressed by confirming evidence than by contradiction, and to be overly influenced by our preferences and preconceptions. The mind's quest for order does seem to condemn us, ironically, to a certain degree of folly. Yet we cannot help but try, in an effort to cope with the future and its uncertainties.

Is it possible to forecast catastrophes? Chris Best, writing in Foresight in June, 1991, thinks not.

"A methodology based on past experience cannot be of much help when most businesses and the risks facing them are changing rapidly in nature. Would the proposed methodology (Rod Strutt's risk assessment suggestion for Monte Carlo simulations), for instance, have predicted the U.K.'s 1987 and 1990 storms? What help would it be in predicting/discovering the new risks which always (in the past at least) take us by surprise - asbestos, pollution, product liability, etc.?"

It is true that we are often surprised by the results. I suggest, however, that a proper and proactive risk management function should be able to act as an early warning device, at least for those who are willing to listen. For example:

- Climatological experts predicted 15 years ago a general weather trend toward more extremes of hot and cold; wind, seismic activity, etc. Did risk managers or insurance underwriters notice? Did they advise their management? Did management listen?

- Asbestos fibers have been known, since biblical times, to be injurious to health. More recently, Paul Brodheur wrote a damaging series of articles on asbestosis in The New Yorker, beginning October 29, 1973, (also reported on in Risk Management Reports in March 1974). They clearly indicated the nature of the problem and the high probability of future claims. Asbestosis has been called by one insurance underwriter "an absolutely unforeseeable disaster". But was it? Did risk managers or underwriters pay attention to the Brodheur article in 1973 ? Did they advise management? Was any action taken?

The problem, then, lies in our latent unwillingness to consider worst case situations. Even if risk management provides some early warning mechanism, will organizations pay heed? This is the key question that Chris Best has raised. If risk management continues to be the long-term warning system in an organizational structure that is clearly oriented toward the present, it may never develop further. 
Fifth, and finally, what will be the role of the insurance industry in the future development of risk management? Has it been a brake on the development of risk management in the past? The conclusion of writers from Burlando to Strutt is clearly yes. The industry has attempted to make "risk management" a euphemism for insurance management and this has thwarted its real development.

Part of the problem lies in the focus of the insurance industry. It has failed to put real emphasis on risk control and risk research (with singular exceptions including, for example, the Swiss Reinsurance Company and the Factory Mutual System). It has overfocused on the predictions of actuaries, who extrapolate the recent past. It has perpetuated the "illusion" that insurance has "solved" a risk problem, when in effect there is more risk sharing than risk transfer, particularly with larger organizations. Insurance underwriters have failed to develop strong risk assessment skills. And, finally, the volatility of the commercial insurance marketplace, leading to the current financial instability of property/casualty insurers in both the U.S. and London, argues that reduced, rather than increased, reliance on conventional insurance may well be necessary.

As a result, the future role of the insurance industry in the development of the risk management discipline will probably be minimal - a conclusion that I state with some regret. True, as Chris Best argues, there may be a strong future for "risk finance specialists", but this should not be confused with holistic risk management.

\section{Conclusions}

Risk management is clearly still evolving as a discipline. All of the current discussion, therefore, is extremely healthy, especially if it leads to practitioners from different disciplines talking and responding to one another. Risk management is and will remain a key ingredient of sound management in a world of "unprecedented uncertainty" (Tom Peters). The risk management challenge is to learn how to live with this uncertainty so that risk can be an acceptable stimulus, rather than an unacceptable threat. Thus, given both the constraints of modern life and the opportunities for the future, the holistic development of risk management appears to be inevitable.

- Risk-based decision-making is becoming more important in an increasingly uncertain world.

- Decision-making under this uncertainty literally encompasses every facet, dimension, and aspect or our lives. To be successful, it must be multi-disciplinary.

- The role, then, of risk management in society is to help individuals and organizations live with uncertainty in a productive and prudent manner.

- Risk management within an organization should be an integral part of both technology and management, in which the assessment, control, and financing of risks, costs, and benefits become a continuing exercise of rational judgment.

Going back to the beginning of this paper and to George Smiley's three questions, I now have my answers:

- "Did it do any good?": Yes, risk management has done some good, but the full significance of its contribution is still to come.

- "What did it do to me?": I have grown intellectually because of it and I have enjoyed my participation in and contribution to the discipline. I still hope to contribute more.

- "What will become of risk management now?": I remain most optimistic about its future contribution to society as a holistic discipline that will enable us to live with risk more intelligently and more confidently. 


\section{REFERENCES}

BARLOW, Douglas A., Dynamic Risks - A Challenge to Risk Management, unpublished paper, November 1989.

BANNISTER, J.E. and BAWCUTT, P.A., Practical Risk Management, Witherby \& Co. Ltd., London, 1981.

BAWCUTT, Paul, Risk Management in the Global Economy, Foresight, July 1991.

BEST, Chris, A New Perspective for Risk Management, Foresight, July 1990.

BRODHEUR, Paul, Annals of Industry: Casualties of the Workplace, The New Yorker, October 29, 1973.

BURLANDO, Anthony, The 1990s: The Decade of Risk Management, Risk Management, March 1990.

COLE, Mitchell J., Risk Management - Beyond Tradition to a Widening Role, Foresight, May 1991.

COVELLO, Vincent T., MENKES, Joshua and NEHNRAJSA, Jim, Risk Analysis, Philosophy and the Social and Behaviorial Sciences: Reflections on the Scope of Risk Analysis Research, Risk Analysis, Vol. 2, No. 2, June 1982.

CROCKFORD, Neil, An Introduction to Risk Management, Woodward-Faulkner, Cambridge, 1980.

FINKEL, Adam H., Confronting Uncertainty in Risk Management, Center for Risk Management, Washington D.C. 1990.

GALlAGHER, Russell B., Risk Management: New Phase of Cost Control, Harvard Business Review, 1956.

GIARINI, Orio, A Macro-Economic Approach, Approaches to Risk Management, Keith Shipton Developments, London, 1977.

GILOVICH, Thomas D., The 'Hot Hand' and Other Illusions of Everyday Life, The Wilson Quarterly, Spring 1991.

GRAUBARD, Stephen R. (editor), Risk, Daedalus, Fall 1990.

GROSE, Vernon L., Managing Risk, Systematic Loss Prevention for Executives, Prentice Hall, 2nd edition, Englewood Cliffs, NJ, 1990.

HAIMES, Yacov Y., Toward A Holistic Approach to Risk Assessment and Management, Risk Analysis, Vol. 9, No. 2, June 1989.

HAIMES, Yacov Y., Total Risk Management, Risk Analysis, Vol. 11, No. 2, June 1991.

HALLER, Matthias, The Aim of Risk Management, Risk Management Approaches, Keith Shipton Developments Ltd., London, 1977.

HAMILTON, Gustav, This is Risk Management, Stockholm, 1988.

HEAD, George L., Collected Essays on Risk Management, American Institute For Property and Liability Underwriters, Malvern, PA, 1986.

HEAD, George L., Risk Management: Our Stake in the Future, National Underwriter, Nov. 5, 1990.

KATZ, Barry M., Technology \& Culture : A Historical Romance, Stanford Alumni Association, Stanford, CA, 1990.

KLOMAN, H. Felix, The Revolt of the Risk Manager, Best's Review, October 1971.

KLOMAN, H. Felix, The Risk Management Revolution, Fortune, July 1976.

KLOMAN, H. Felix, Risk Management: 1990 and Beyond, Risk Management, March 1984. 
KLOMAN, H. Felix, Risk Management... By Many Other Names, Risk Management, June 1987.

KLOMAN, H. Felix, Risk Management Agonistes, Risk Analysis, Vol. 10, No. 2, June 1990.

KONNER, Melvin, Why the Reckless Survive, Viking, New York, 1990.

LOWRANCE, William W., Comparative Product-Life-Cycle Confrontation of Risks, paper to Conference on Risk Prevention, Zurich, January 1989.

McGANNON, William, Hang Onto Your Spreadsheets, Statistical Wizards, and Ask These Questions, Insight, March 1991.

McNEILL, William H., Control and Catastrophes in Human Affairs, Daedalus, Winter, 1989.

MURPHY, Dana H., Dissecting a Cliche: Our Risk-Averse Society, Contingencies, May/June 1991.

PETERS, Tom, Tomorrow's Companies, The Economist, March 4, 1989.

ROWE, William P., An Anatomy of Risk, Wiley, New York, 1977.

SIVER, Edward W., Risk Management: Practical Ideas and Applications, Risk \& Insurance Management Society Publishing Inc., New York, 1991.

SJÖBERG, Lennart, Risk and Safety, Allen \& Unwix, London, 1987.

SNIDER, H. Wayne, Buyers Must Justify Professional Claims, National Underwriter, Nov. 24, 1955.

SNIDER, H. Wayne, Risk Management, Where Do We Go From Here, Risk Management, Aug./ Sept. 1971.

SNIDER, H. Wayne, Risk Management: A Retrospective View, Risk Management, April 1991.

STRUTT, R.S. G., A Definitive Technique for Risk Assessment?, paper to First Institute of Risk Management Conference, London, May 1991.

STRUTT, R.S. G., The Reality of Risk Management, paper to AIRMIC conference, Cambridge, April 1989.

WACHBROIT, Robert, What's in a Risk?, Philosophy \& Public Policy Report, University of Maryland, Winter, 1991.

WARREN, David, The Risk Manager as Manager, The Warren Report, No. 112, May 1991.

WILDAVSKY, Aaron, Searching for Safety, Transaction Books, New Brunswick, N. J., 1988.

ZAPOLSKI, Harvey, The Politics of Risk, Daedalus, Fall 1990. 